\title{
O facto economico no ponto de vista sociologico
}

A interdependencia dos phenomenos economicos e dos phenomenos sociaes é um dos aspectos mais salientes do dynamismo historico. A principio pouca importancia se attribuia a esta interdependencia, tanto que entre os phenomenos sociologicos, geralmente classificados sob criterios artificiaes, não figuravam os economicos como elementos integrantes do viver das sociedades. Nas classificações que se faziam das sciencias sociaes tambem se omittia a economia politica, bastando citar a de Von MoHL que apenas schematizava a sciencia dos costumes, a do direito, a politica e a historia. Por outro lado, os estudos economicos, aferrados ao individualismo estreito da escola classica, só um material escasso podiam offerecer á systematização scientifica.

Hoje seria ocioso apontar as classificações em que o facto economico vem inserto com os sociaes, quer como substrato destes, quer como parte componente da vida collectiva. Na de G. DE Greef, uma das mais logicas, os phenomenos economicos occupam o primeiro plano segundo o principio da generalidade decrescente e complexidade crescente que A. Comte adoptou na seriação dos conhecimentos positivos.

Para o eminente sociologo os phenomenos economicos são os mais simples, os mais geraes, os que correspondem ás necessidades biologicas do aggregado, á vida de nutrição dos organismos sociaes: 
"As nossas buscas levaram-nos a reconhecer que os phenomenos economicos são os mais geraes e os mais simples da vida collectiva; a nutrição, isto é, o consumo e a producção das utilidades assimilaveis é a condição sine qua non de toda a existencia social; desta, ella é a funcção mais universal, a mais constante; é impossivel mesmo figurar um facto qualquer sem apoial-o em certas formas economicas; supprimi a vida economica das sociedades, e tudo se desmorona: vida affectiva ou familial, vida artistica, vida intellectual, vida moral, até o direito não tem mais razão de ser, e a direcção politica collectiva torna-se impotente e sem objecto"

E' muito conhecida a importancia que a escola marxista attribue aos phenomenos economicos na formação $e$ desenvolvimento dos grupos sociaes, para que della se faça aqui um exposto detalhado; pode-se affirmar que a tal escola deve a sciencia economica o feitio sociologico que lhe vêm imprimindo eminentes economistas e sociologos da Europa e da America, cujos nomes é desnecessario enumerar.

Em uma critica que faz KARL MARx ás idéas reinantes, até o seu tempo, nos dominios da economia politica, lê-se que "as relações juridicas e as formas politicas não podem ser comprehendidas por si mesmas, nem tambem se explicam pelo que se chama desenvolvimento geral do espirito humano, mas têm as suas raizes nas condições da vida material. Na producção social indispensavel á sua vida quotidiana, os homens contraem certas relações ao mesmo tempo independentes da sua vontade, necessarias, determinadas. Estas relações de producção correspondem a certo grau de desenvolvimento de suas forças productivas materiaes. A totalidade destas relações forma a estructura economica da sociedade, a base real sobre que se eleva uma superstructura economica e juridica e a que correspondem formas determinadas de consciencia social. A maneira de produzir da vida material determina de um modo geral o processo social, politico e intellectual da vida" 
Explica-se de accordo com este modo de ver a passagem das sociedades do regimen feudal para o regimen capitalista, movimento iniciado no correr do seculo XVII, isto é, quando o capital começou a ser como que o nervo da organização industrial; explica-se a substituição dos mercados regionaes pelo mercado nacional, e o desdobramento dos mercados nacionaes em mercado internacional, cuja expansão cria uma vasta cadeia de interesses economicos, juridicos e politicos entre os povos mais afastados pela situação geographica, pela cultura, pela indole, pelas tradições. Afinal, descobre esta doutrina na producção das riquezas a força motriz das mutações historicas nas differentes aggremiações humanas, nos nucleos pouco heterogeneos das populações primitivas, como nos aggregados complexos que no planeta formam as nações e em cada nação as classes sociaes.

Outra escola que confere ao facto economico um caracter eminentemente sociologico é a que tomou entre os economistas allemães a denominação de escola historica: o facto economico é um dos aspectos do evolver das sociedades, entrelaçado com os costumes, com o direito, com as regras de conducta collectiva, facto que se corporifica em instituições, cujo molde é talhado pelo genio, pela historia, pelo modus vivendi de cada grupo. Eis em resumo a opinião de um dos proceres desta escola:

"Pelo costume o homem cria um novo mundo da natureza, o mundo da civilização. $O$ homem alimenta-se instinctivamente, porém os costumes induzem-no a alimentarse, o uso cria as vestimentas, a moda, todos os productos de uma ordem mais elevada. A fome impelle o caçador a matar a caça, o costume attribue-lhe a posse exclusiva della e cria assim a propriedade, de onde nascerá o direito de successão. Sem costumes bem estabelecidos, não ha mercado, nem troca, nem divisão do trabalho, nem castas, nem escravos, nem governos".

Estudos precedentes não só de economistas, mas tambem de ethnographos, de sociologos e de historiadores pa- 
tenteiam a influencia do phenomeno economico na origem e evolver da vida social.

Morgan, que divulgou profundas e pacientes observações sobre as sociedades primitivas, diz ser "provavel que as grandes epocas do progresso humano se identificam mais ou menos directamente com o desenvolvimento dos meios de subsistencia"; as mudanças que se passam no direito e na politica correspondem ás mudanças de forma e constituição da propriedade; a transição do clan ao regimen patriarchal, da familia polygamica á monogamica, assenta em uma base de ordem economica. O mesmo fundamento de ordem economica attribuiram ás sociedades domesticas, entre outros, Engels, Grosse e Cusow.

Entre os sociologos é commum a idéa de integrar-se o facto economico ao mundo social. Um dos mais famosos, Gumplowicz, chega a subordinar o estudo das acções economicas a um criterio puramente sociologico. Induznos a pensar que, emquanto prevalecer na sciencia economica a velha doutrina individualista, nada de positivo, de exacto se poderá colher nesse dominio. Ao individuo impellido por sentimentos egoistas ou altruistas, sentimentos que o fazem agir economicamente, oppõe grupos sociaes que lutam entre si, que absorvem uns aos outros, no interior dos quaes a divisão do trabalho cria diversos typos socio-economicos: uns, vivendo em campos ferteis, tornam-se plantivoros e mais tarde agricultores; outros, vivendo á margem dos rios ou dos mares, entregam-se á pesca e depois se tornam navegantes e commerciantes; os que habitam os bosques e se alimentam da caça, se transformam em criadores; finalmente, os que habitam territorios onde ha escassez dos meios de subsistencia, estes se entregam á pilhagem, tornam-se guerreiros e fundadores de Estados.

Como Schaffle, Kovalewsky e muitos outros, crê aquelle sabio professor que a economia politica não pode prescindir das luzes da sociologia. Por outro lado, historiadores de renome salientam o papel do phenomeno economico actuando como factor predominante, ou como um 
dos grandes factores, na successão dos acontecimentos que marcam phases distinctas na vida de um povo.

Guiraud, que se deu a estudos historicos de economia politica, affirma que "as questões economicas tinham nas sociedades antigas como na nossa, uma influencia preponderante" Cicotti, Pohlmann, Nietzsche, Mommsen não se esqueceram de apontar as condições de ordem economica entre as que influiram na formação e no progresso das instituições da antiguidade; e relativamente á historia medieval e aos tempos modernos o mesmo criterio seguiram G. DEs Marez, ao descrever as lutas sociaes em Flandres na edade media, J. Luchaire, no seu livro sobre as democracias italianas, Bernstein quando se refere ás correntes socialistas dominantes durante a Revolução ingleza e LAMPRECHT que faz depender do factor economico o desenvolvimento social e politico da Allemanha medieval.

A conclusão a tirar-se deste exposto summario é que uns procuram subordinar a vida social, sob os seus multiplos aspectos, ao phenomeno eccnomico, aos processos de producção e circulação das riquezas, ao passo que outros consideram a vida economica um modo de ser da vida collectiva, sendo a sciencia economica neste caso, para economistas como Cliffe-Leslie, Ingram, Harrison, Cognetri de Martis, Vierkandt, um ramo da sociologia que se não deve estudar em separado, mas tendo-se sempre em conta os outros departamentos da vida social.

O nosso modo de pensar é que o phenomeno economico não pode ser por si só o substrato das outras formas da evolução social, da religião, da moral, da arte, do direito, da politica, nem tão pouco pode ser encarado exclusivamente no ponto de vista sociologico.

0 erro da theoria materialista da historia, já escrevemos em outra parte, está em reduzir ao phenomenismo economico todas as manifestações da vida social. Mas, como 
no organismo, as funcções puramente nutritivas não se confundem com as funcções mentaes, assim na sociedade ha factos que se não podem tomar como simples epiphenomenos do facto economico. Si este actua de modo profundo no evolver social, soffre por seu turno a influencia da religião, dos costumes, do direito, da politica. Pode-se dizer como R. Stammler que "não é philosophico pretender que uma categoria qualquer de relações sociaes seja a causa geral ou a explicação das outras relações sociaes"; todas se prendem não só por laços de causalidade, mas principalmente por laços estreitissimos de interdependencia.

Como exemplo citemos a religião, a arte, a moral e a politica. Nas sociedades primitivas e entre os selvagens percebe-se com clareza que si a vida economica concorre para a formação dos mythos, observa-se por outro lado que o trabalho, o commercio, o consumo das riquezas são regulados pelo rito, pelo cerimonial dos cultos, que lhes imprime muitas vezes um relevo rigorosamente formalistico.

Sabe-se pela voz de Hesiodo que entre os gregos designava Jupiter um dia de descanço em cada mez, e outros para taes e taes occupações. E Curtius, falando tambem da Gregia antiga, diz que "os logares sagrados do paiz eram centros de transações commerciaes consideraveis que achavam a paz e a segurança nos portos sagrados, nas vias sacras e na vizinhança dos templos, ao passo que no resto do mundo reinava a lei selvagem do mais forte. De Roma nos conta Mommsen que as feiras ali coincidiam com a festa no templo federal sobre o Aventino; o repouso prescreviam-no os deuses a senhores e escravos, e a vendagem era precedida de cerimonias religiosas que celebrava o Flamen Dialis. Na antiga Inglaterra, escreve Mrs. GreEN, era a egreja o local onde "a communidade sempre se reunia para toda especie de negocios, para ouvir as contas da cidade, para repartir as terras possuidas em commum, para estabelecer concessões de propriedades, para ajustar soldados e eleger o prefeito" 
Ainda hoje, no interior dos paizes onde a população é pouco densa e os meios de transporte difficeis, as feiras e as festas religiosas se realizam no mesmo dia. Nos sertões brasileiros são de alta importancia para o productor, para o commerciante, para a massa total dos consumidores, os grandes festejos consagrados pelo catholicismo aos santos que mais prestigio gosam entre os seus sectarios.

A arte e a vida economica egualmente se interdependem: ora são as condições economicas que retardam ou estimulam o desenvolvimento das artes; ora são as artes que imprimem a phenomenos economicos um valor esthetico. Assim, os objectos de luxo tanto se estimam economicamente como artisticamente. Segundo Grosse, "entre os povos primitivos uma forma da arte corresponde por toda a parte a uma forma dada de producção. Hornes, si bem que com exaggero, crê que os povos caçadores cultivam uma arte realista, e os industriaes uma arte idealista. Mais exacto, porém, é o que se dá com as artes plasticas; ellas "são sempre extremamente desenvolvidas nos povos caçadores: porque a caça lhes dá ao mesmo tempo em alto grau a faculdade de ver, de observar e de reter as formas naturaes, e tambem desenvolve nelles os apparelhos motores e sensiveis que entram em actividade durante o trabalho artistico"

Quanto á moral, é bem conhecida a preoccupação dos economistas relativamente ás connexões que ella offerece com a vida economica. Basta que se abra qualquer compendio de economia politica para têr-se a certeza de quanto os problemas moraes impressionam aos espiritos praticos como aos theoricos; diz-se mesmo que a questão social é simplesmente uma questão moral, e são innumeras as associações humanitarias em cujo programma figura o desejo de reformar a sociedade, ou esta ou aquella classe social, pela melhoria das condições economicas em que se encontram.

$\mathrm{Na}$ vida politica dos grupos sociaes resalta o mesmo phenomeno de interdependencia e de reacções reciprocas: 
si os systemas de propriedade, de defender a riqueza collectiva e individual dos assaltos do inimigo externo, si a garantia dos direitos do individuo aos meios de subsistencia; si o mecanismo da troca, as crises que assolam as classes menos favorecidas, as aspirações de bem-estar das massas populares, imprimem modificações sensiveis á estructura e ao funccionamento do poder politico, este, por sua vez, reage sobre o conjuncto de relações, sobre o curso dos factos, sobre o feitio das instituições, em que se crystaliza o dynamismo das forças economicas.

No ponto de vista doutrinario é grande o valor scientifico, como vimos anteriormente, que os economistas da escola historica conferem ao papel dos costumes no desenvolvimento da vida economica e das suas instituições.

Exaggeram, entretanto, essa influencia, porque o costume está, como facto social, ligado a circumstancias multiplas entre ellas a de ordem economica; antes de ser um facto gerador de relações sociaes, resulta de outros que o precederam; estabelece-se e perpetua-se após a repetição de uma seria de actos, identicos ou analogos entre si, actos que praticam individuos associados no mesmo habitat, ou ligados pelos mesmos interesses, sendo estes economicos, moraes, juridicos, etc. Em summa, o costume emana de uma necessidade, de um sentimento, de uma crença, de uma idéa, que se irradia de uma camada a outras camadas do mundo social, fixando-se em regras, incarnando-se em symbolos, petrificando-se em habitos, constituindo-se uma especie de bloco de granito, sobre o qual se elevam e se mantêm as civilizações estaveis.

$O$ facto economico tem as suas raizes nas necessidades vitaes dos seres, e si estes vivem associados, reveste-se naturalmente de uma forma social. O que se dá com a vida economica, acontece egualmente com a religião, com a moral, com a arte: são factos que assentam em um substrato physio-psychologico, mas tomam um relevo sociologico, porquanto se manifestam no individuo fazendo parte de uma sociedade e por esta educado. Ella resulta de con- 
dições de ordem physica, vital, psychıca e social: o clima, a topographia do solo, as vias naturaes de communicação, as jazidas de metaes preciosos, a chimica dos terrenos são a materia prima que o trabalho physico e intellectual modifica, transforma e utiliza; a flora e a fauna, os processos de multiplicação e de aperfeiçoamento das especies; as qualidades ethnicas do grupo social, o genero de alimentação, a natalidade e a mortalidade entram entre as condições de ordem biologica; o modo por que o homem encara as relações economicas, o valor das cousas, o instincto de acquisição dos meios de subsistencia, o sentimento dá propriedade; novos gostos, novas necessidades que nascem e se apuram com a civilização, formam um copioso manancial de experiencias que egualmente interessam ao economista e ao psychologo. Os systemas de propriedade, a regulamentação juridica das actividades productivas e da circulação das riquezas, a organização de classes, o mecanismo financeiro do Estado etc. são factos communs á economia, ao direito e á politica.

Assente sobre esse complexo de condições, a vida economica torna-se o campo de uma sciencia autonoma com os seus processos de busca, com principios inherentes á sua propria systematização; não é um simples capitulo da sociologia, é uma das suas vastas especializações; ao mesmo tempo que relações intimas se estabelecem entre ella e a psychologia, a biologia e as sciencias do mundo inorganico. Certamente não é á sociologia que compete dar á economia esclarecimentos sobre o grau de resistencia do individuo ao trabalho; sobre o espirito de iniciativa de um industrial; sobre as cogitações profundas do espirito humano que conduzem ás grandes descobertas; mas á biologia e á psychologia que estudam as condições vitaes e psychicas do organismo que, antes de se adaptar a um ambiente social, se adapta ao ambiente physico. A fertilidade ou a esterilidade do solo, a amenidade ou o rigor do clima, os accidentes geographicos actuam de modo particular na economia individual e de modo geral na economia do grupo. Em 
synthese, o phenomeno economico é uma fórma de adaptação que se procede por uma serie de reacções organicas, psychicas e sociaes correspondentes a uma serie de necessidades de conservação e desenvolvimento, tambem organicas, psychicas e sociaes, do individuo e do aggregado.

DR. JOAQUIM PIMENTA

(Professor da Faculdade de Direito do Recife) 